\title{
In-Situ Tests on Silica Aerogel-Based Rendering Walls
}

\author{
Inês Flores-Colen ${ }^{1}$, Marco Pedroso $^{2}$, António Soares ${ }^{3}$, Maria da Glória Gomes ${ }^{4}$, Nuno \\ M. M. Ramos ${ }^{5}$, Joana Maia ${ }^{6}$, Rui Sousa ${ }^{7}$, Hipólito Sousa ${ }^{8}$ and Luís Silva ${ }^{9}$ \\ ${ }^{1}$ Associate Professor, CERIS, Instituto Superior Técnico, Universidade de Lisboa, Av. Rovisco Pais, \\ 1049-001 Lisbon, Portugal, ines.flores.colen@tecnico.ulisboa.pt \\ ${ }^{2} \mathrm{PhD}$ student, CERIS, Instituto Superior Técnico, Universidade de Lisboa, Av. Rovisco Pais, 1049- \\ 001 Lisbon, Portugal, marco.pedroso@tecnico.ulisboa.pt \\ ${ }^{3}$ Post-doc researcher, CERIS, Instituto Superior Técnico, Universidade de Lisboa, Av. Rovisco Pais, \\ 1049-001 Lisbon, Portugal, ortiz.soares@gmail.com \\ ${ }^{4}$ Assistant Professor, CERIS, Instituto Superior Técnico, Universidade de Lisboa, Av. Rovisco Pais, \\ 1049-001 Lisbon, Portugal, maria.gloria.gomes@tecnico.ulisboa.pt \\ ${ }^{5}$ Assistant Professor, CONSTRUCT, Faculdade de Engenharia, Universidade do Porto, Rua Dr. \\ Roberto Frias, 4200-465 Porto, Portugal,nuno.ramos@fe.up.pt \\ ${ }^{6}$ Researcher, CONSTRUCT, Faculdade de Engenharia, Universidade do Porto, Rua Dr. Roberto Frias, \\ 4200-465 Porto, Portugal, joanamaia@fe.up.pt \\ ${ }^{7}$ Researcher, CONSTRUCT, Faculdade de Engenharia, Universidade do Porto, Rua Dr. Roberto Frias, \\ 4200-465 Porto, Portugal, ruysousa@fe.up.pt \\ ${ }^{8}$ Associate Professor, CONSTRUCT, Faculdade de Engenharia, Universidade do Porto, Rua Dr. \\ Roberto Frias, 4200-465 Porto, Portugal, hipolito@fe.up.pt
}

\begin{abstract}
In this paper, two aerogel-based renders are characterized based on in-situ testing of walls prototypes. The in-situ tests to assess the mechanical performance are: pull-off, surface impact tests and compressive strength on collected samples. The physical performance includes the water resistance and thermal conductivity coefficient. The tests carried out to assess water-resistance are: Karsten tube, moisture meter and capillary water absorption of collected samples. The thermal performance was tested based on infrared thermography and thermal conductivity transient method.

The combination of these in-situ tests allowed a better performance characterization of the aerogelbased renders and characterized the applied renders. These results were carried out under two national research projects (Nanorender and P2020 PEP).
\end{abstract}

Keywords: In-Situ Tests, Renders, Aerogel, Walls, Performance.

\section{Introduction}

On-site performance testing of renders avoids subjective diagnosis and contribute to a better understanding of render behavior under natural exposure conditions. In-situ techniques on conventional renders have been applied on several studies (Flores-Colen et al., 2011; Duarte et al., 2020; Menezes et al., 2015; Santos et al., 2013) such as ultra-sound; pull-off; surface impact test; Karsten tube; moisture meter; and infrared thermography. Also, compressive strength and capillary water absorption have been carried out on render samples collected from on-site. The study of aerogel (Garrido et al., 2019) and aerogel-based renders is increasing due to their excellent thermal performance and application on thermal rehabilitation of walls, with decreased thicknesses solutions when compared with other conventional thermal renders. In the literature there are already a few number of studies that focus on in-situ testing of aerogel-based 
renders, but mainly on the hygrothermal behavior of these renders based on numerical simulations (Fantucci et al., 2020; Fenoglio et al., 2018; Ibrahim et al., 2014; Stahl et al., 2017).

In this paper, several in-situ techniques are applied on wall prototypes with different formulations of aerogel-based renders, in order to discuss the mechanical, water resistance, and thermal performance. The tested formulations (renders A and B) were developed in two national research projects. In Nanorender project (2012-2015), funded by FCT (Foundation for Science and Technology) PTDC/ECM/118262/2010 ("Nanorender: Performance of nanoaerogel silica-based renders" 2015), a cement-based aerogel render, with fly ash and lightweight co-aggregates was developed reaching a good balance between thermal conductivity $(0.088 \mathrm{~W} / \mathrm{m} . \mathrm{K})$ and compressive strength (1.03 MPa). In PEP project (2016-2019), funded by COMPETE 2020/Portugal P2020POCI-01-0247-FEDER-017417, a new aerogel-based render was developed (thermal conductivity of $0.028 \mathrm{~W} / \mathrm{m} . \mathrm{K}$ ) with compressive strength above $0.2 \mathrm{MPa}$ and water vapour diffusion resistance coefficient below 15. Only some results are discussed for two specific aerogel-based renders formulations in order to discuss the potential of in-situ techniques to assess in-service performance.

\section{Experimental Program}

\subsection{Materials}

The render $\mathrm{A}^{\mathrm{Aero}+\mathrm{EC}}$ has in its composition: cement CEM II B/L $32.5 \mathrm{~N}, 1 \%$ of surfactant agent and $0.075 \%$ cellulose ether, in weight relative to the total mixture mass. The mixing procedure was initially manual and with 1015-11, and the wate commercial supercritical showed problems in the application of a composition with 100\% Thus, the incorporation of the expanded clay
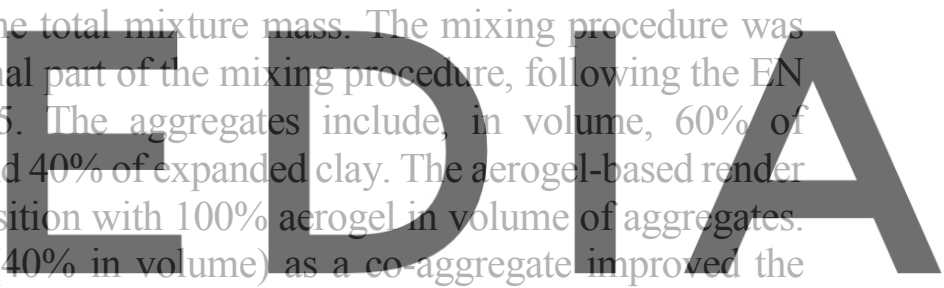

mortar consistency and allowed a quick and easy application of the render. A render with only

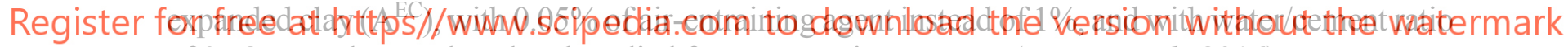
of 0.78, was also produced and applied for comparative purpose (Lazera et al., 2016).

The render $\mathrm{B}^{\text {Aero }}$ is composed by a blend of mineral binders, rheological agents, resins, hydrophobic agents, lightweight fillers, containing a commercial supercritical hydrophobic hybrid silica aerogel as a lightweight and thermal insulation aggregate. The silica aerogel granules represent around $58 \%$ in volume or a total of $37 \%(\mathrm{~m} / \mathrm{m})$ in the weight, both for the mixture powder. The water/binder ratio was 1.33 (Pedroso et al., 2019; Sousa et al., 2019). This render has also a multilayer coating composed by a basecoat layer, fibreglass mesh, key coat, and an acrylic finishing coat (Pedroso et al., 2019).

\subsection{Wall Prototypes}

The renders $\mathrm{A}^{\mathrm{Aero}+\mathrm{EC}}$ and $\mathrm{A}^{\mathrm{EC}}$ (Figure 1 , a) were manually applied with $4 \mathrm{~cm}$ thickness on an opening of a brick wall, with $15 \mathrm{~cm}$ of thickness and $40 \times 45 \mathrm{~cm}^{2}$ dimensions. The curing conditions were at ambient air temperature (average of $15^{\circ} \mathrm{C}$ ) during 28 days. The surface of the render was periodically moistened in the first days of curing, a plastic sheet covered the wall (Figure 1, b). The render $\mathrm{B}^{\text {Aero }}$ was mechanically applied with $5.5 \mathrm{~cm}$ of thickness on a lightweight concrete masonry wall with $3 \times 3.6 \mathrm{~m}^{2}$ (Figure 1, c and d). The curing conditions were at ambient air temperature 
(average of $20^{\circ} \mathrm{C}$ ) during 28 days without any humidification of the render surface.

\subsection{Testing Procedures}

Several techniques were carried out on the wall prototypes: adhesive strength on substrates (EN 1015-12 - pull-off; water permeability under low pressure (LNEC FE Pa 39.1/RILEM no II.4) Figure $2 \mathrm{a}$; pendulum hammer index (RILEM MS-D.7), Figure $2 \mathrm{~b}$; hardness impact (LNEC Fe Pa 25), Figure $2 \mathrm{c}$; thermal conductivity coefficient (ASTM D5930) and also following the test recommendations by Gomes et al. (2018), Figure 2 a; Tramex moisture meter (Figure $2 \mathrm{~d}$ ), and FLIR infrared camera.

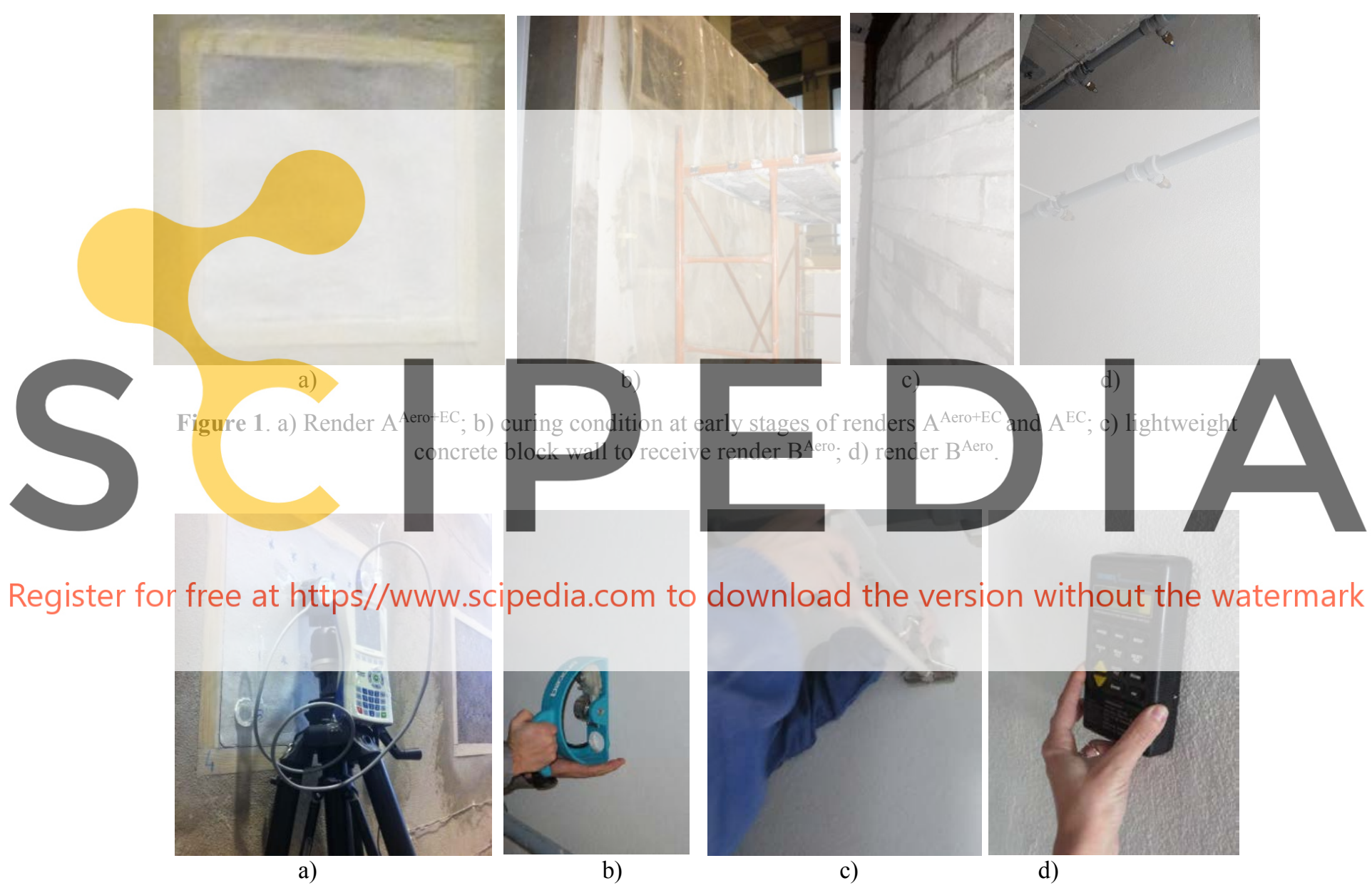

Figure 2. a) Thermal conductivity, Karsten tube in render $A^{\text {Aero+EC; }}$ b) pendulum hammer, c) impact test with Martinet Baronnie device; d) moisture meter in render $\mathrm{B}^{\text {Aero }}$.

The prototypes were installed in climatic chambers with an internal controlled environment. Some samples were collected and prepared for compressive strength and capillary water absorption tests, with and without the multilayer finishing system (when applicable). All the renders were tested at 28 days of curing. 


\section{Results}

Table 1 presents some of the experimental results obtained for aerogel-based renders A and B. These results showed that the applied thermal renders have good thermal performance. The incorporation of aerogel improves the thermal characteristics (for example compare $\mathrm{A}^{\mathrm{EC}}$ and $\mathrm{A}^{\text {Aero+EC }}$ with the same formulations, 0.1359 for $\mathrm{A}^{\mathrm{EC}}$ and 0.1200 for $\left.\mathrm{A}^{\text {Aero+EC}}\right)$ ).

Furthermore, the thin coating of the multilayer coating system misleading the in-situ measurement of the thermal conductivity $\left(0.034\right.$ for $\mathrm{B}^{\text {Aero }}$ and $0.120 \mathrm{~W} / \mathrm{m} . \mathrm{K}$ for the mortar with finish coating, respectively). The latter measurement should not be consider because two requirements of this technique are not accomplished: the measurements on a homogeneous material and the minimum thickness. Aerogel-based renders have low compressive strength values and low compacity. However, they have higher deformability, lower pendulum hammer index and higher notch diameter in the Martinet-Baronnie device. If necessary, depending on the surface requirements, a protective multilayer coating system could improve or maintain accentable values of surface resistance (e.g. B ${ }^{\text {Aero }}$ has the same surface resistance than the $\mathrm{A}^{\mathrm{Aero}+\mathrm{EC}}$ without a finish layer).

Table 1. Results aerogel-based renders A and B.
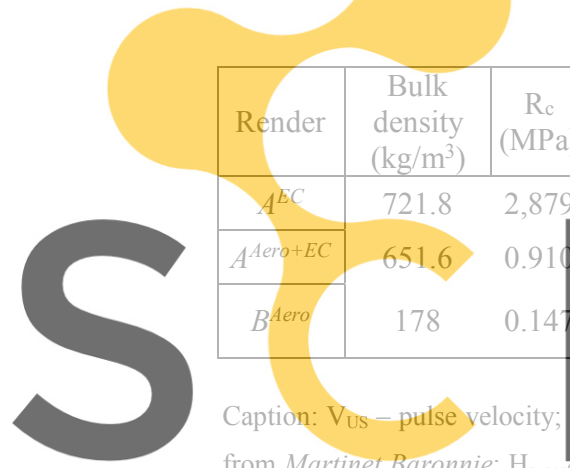

surfacendisture: $\lambda$ - thermal
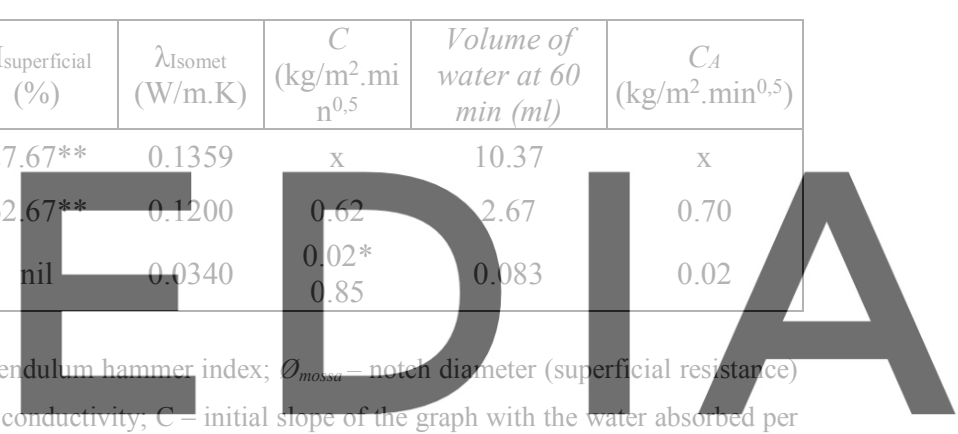

area over time; $C_{4}$ - water absorption under low pressure from Karsten tube (Equation 1), where $\mathrm{Q}=$ volume of water absorbed (ml). D is

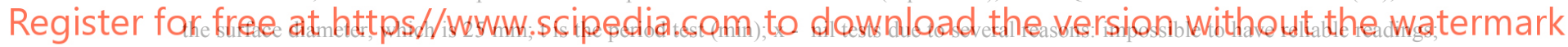

reduced thickness of the collected samples from the walls; * with multilayer finishing system: ** with $41 \%$ of relative air humidity.

$$
C A=\frac{Q \cdot 10^{-3}}{D^{2} \cdot\left(\frac{\pi}{4} \cdot 10^{-6} \cdot \sqrt{t}\right)}
$$

The presence of expanded clay guarantees values of mechanical strength above the minimum of $0.4 \mathrm{MPa}$ from EN 998-1, for thermal renders however significantly increases the thermal conductivity coefficient (from 0.034 of $\mathrm{B}^{\text {Aero }}$ for 0.12 for $\mathrm{A}^{\text {Aero+EC }}$ ) (Júlio et al., 2016). Therefore, both lightweight aggregates and paste formulation contribute to the balance between compressive strength and thermal conductivity.

In terms of water resistance, aerogel-based renders tend to have high water absorption (capillary suction or under low pressure) due to their high porosity, despite the hydrophobic nature of the aerogel and the introduction of more entraining agents (from 2.67 to $10.37 \mathrm{ml}$ in $\mathrm{A}^{\text {Aero+EC }}$ to $\mathrm{A}^{\mathrm{EC}}$. The water absorption due to capillary requirements for renders to be applied to external walls is not accomplished $\left(0.85\right.$ and $0.62 \mathrm{~kg} / \mathrm{m}^{2} \cdot \mathrm{min}^{0.5}$, in table 2 , for aerogel-based renders) according to EN 998-1 (CEN, 2010). However, a compatible multilayer coating reduces the water absorption of the render system (from 0.85 to $0.02 \mathrm{~kg} / \mathrm{m}^{2} \cdot \mathrm{min}^{0.5}$ in $\mathrm{B}^{\text {Aero }}$ ). 
The experimental results also showed that aerogel-based renders have drawbacks in adhesive strength. The majority of the results were nil, or the values were too low (0.04 MPa with cohesive rupture). Because of the low weight of these renders and low susceptibility to thermal gradients, the low adhesion values can be accepted. However, some admixtures could be added with this purpose). The results also showed that less intrusive pull-off technique should be adapted in the future to have a more reliable test to assess the adhesion of these renders and other lightweight thermal mortars. Furthermore, the moisture meter confirmed the presence of surface moisture on the render $\mathrm{A}^{\text {Aero+EC }}$ after 28 days of curing in laboratory conditions. In render $\mathrm{B}^{\text {Aero }}$, the values were nil due to the multilayer coating system. In addition, in this render, the infrared thermography was used and no significant differences of the superficial temperature was found, therefore concluding that there is a uniformity of the thermal render, without the presence of moist areas.

\section{Conclusions and Future Developments}

This paper contributes to the discussion of the performance of aerogel-based renders on walls prototypes. The results showed that these renders have excellent thermal behaviour but with specific characteristics in terms of compressive strength and water resistance.

The in-situ testing and lab testing on the collected samples confirm the mechanical, waterresistance and thermal performance of the applied aerogel-based renders. These renders tend to have lower compressive strength, low compactness but high surface deformability. Because of the

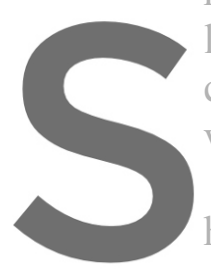
low weight of these rencer conductivity), the solut values.

The water resistance hydrophobic nature
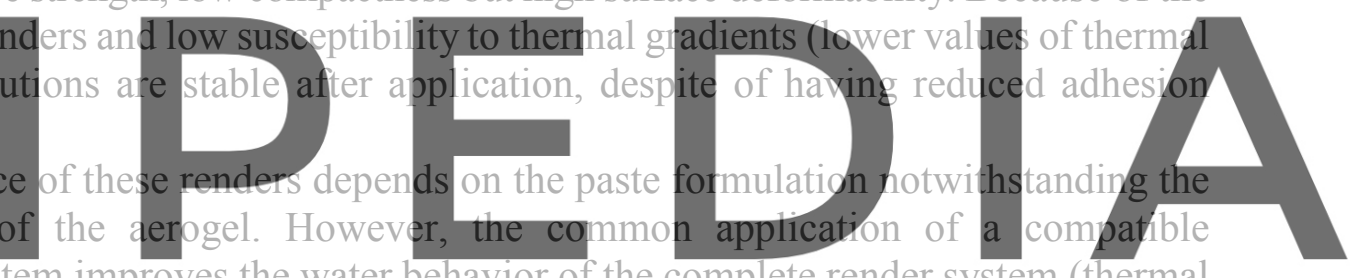

multilayer coating system improves the water behavior of the complete render system (thermal

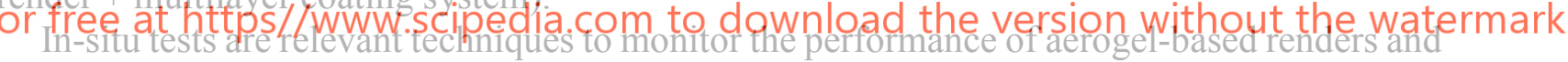

to give additional information to numerical simulations of these renders. However, some drawbacks can be highlighted, specially when multilayers systems are applied. For example, in-situ measurements of thermal conductivity with ISOMET technique are reliable only on aerogel-based renders without thin coating systems. Further research should discuss the thermal performance of these multilayer systems based on the thermal resistance.

\section{Acknowledgements}

The authors gratefully acknowledge the support of CERIS Research Centre, IST - University of Lisbon, Portuguese FCT - Foundation for Science and Technology, Saint-Gobain Weber Portugal, and COMPETE 2020 project POCI01-0247-FEDER-017417. The second author also wants to thank FCT for PhD grant SFRH/BD/132239/2017.

\section{ORCID}

Inês Flores-Colen: https://orcid.org/0000-0003-4038-6748

Marco Pedroso: https://orcid.org/0000-0002-8119-6847

António Soares: https://orcid.org/0000-0002-0377-1295

Maria da Glória Gomes: https://orcid.org/0000-0003-1499-1370

Nuno M. M. Ramos: https://orcid.org/0000-0002-5331-7429 
Inês Flores-Colen, Marco Pedroso, António Soares, Maria da Glória Gomes, Nuno Ramos, Joana Maia, Rui

Sousa, Hipólito Sousa and Luís Silva

Joana Maia: https://orcid.org/0000-0001-5036-8581

Hipólito Sousa: http://orcid.org/0000-0001-8335-0898

Rui Sousa: http://orcid.org/0000-0003-3855-3252

\section{References}

Duarte, R., Flores-Colen, I., de Brito, J. and Hawreen, A. (2020). Variability of in-situ testing in wall coating systems - Karsten tube and moisture meter techniques. Journal of Building Engineering, 27, 100998. doi: 10.1016/j.jobe.2019.100998

Fantucci, S., Fenoglio, E., Serra, V., Perino, M., Dutto, M. and Marino, V. (2020). Hygrothermal Characterization of High-Performance Aerogel-Based Internal Plaster. In J. Littlewood, R. Howlett, i A. Capozzol, \& L. Jain (Eds.), Sustainability in Energy and Buildings. Smart Innovation, Systems and Technologies (pp. 259-268). doi: 10.1007/978-981-32-9868-2_22

Fenoglio, E., Fantucci, S., Serra, V., Carbonaro, C. and Pollo, R. (2018). Hygrothermal and environmental performance of a perlite-based insulating plaster for the energy retrofit of buildings. Energy and Buildings, 179, 26-38. doi: 10.1016/j.enbuild.2018.08.017

Flores-Colen, I., Manuel Caliço Lopes de Brito, J. and Peixoto de Freitas, V. (2011). On-site performance assessment of rendering façades for predictive maintenance. Structural Survey, 29(2), 133-146. doi: 10.1108/02630801111132812

Garrido, R., Silvestre, J. D., Flores-Colen, I., Júlio, M. de F. and Pedroso, M. (2019). Economic assessment of the production of subcritically dried silica-based aerogels. Journal of NonCrystalline Solids, 516(January), 26-34. doi: 10.1016/j.jnoncrysol.2019.04.016

Gomes, M. G., Flores-Colen, I., da Silva, F. and Pedroso, M. (2018). Thermal conductivity measurement of thermal insulating mortars with EPS and silica aerogel by steady-state and

transient methods. Construction and Building Materials, 172, 696-705. doi: 10.1016/j.conbuildmat.2018.03.162

Ibrahim, M., Wurtz,

performance of exterior

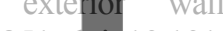

Júlio, M. F., Soares

renders with lightweight

performance. Construction

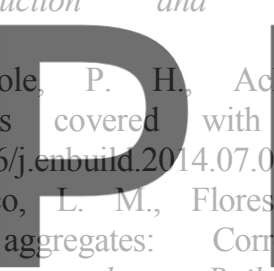

10.1016/j.conbuildmat.2016.07.103

and

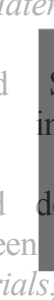

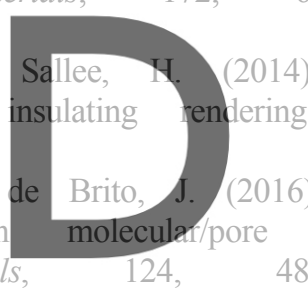

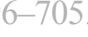

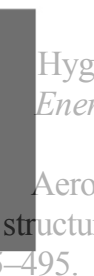

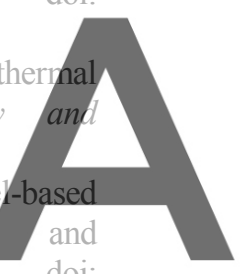

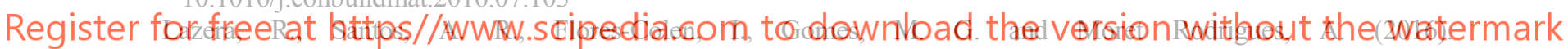
Experimental study of mechanical and physical performance of thermal mortars. In L. Villegas, I. Lombillo, H. Blanco, \& Y. Boffill (Eds.), Rehabend 2016 Euro-American Congress, Burgos - Spain.

Menezes, A., Glória Gomes, M. and Flores-Colen, I. (2015). In-situ assessment of physical performance and degradation analysis of rendering walls. Construction and Building Materials, 75, 283-292. doi: 10.1016/j.conbuildmat.2014.11.039

Pedroso, M., Flores-Colen, I., Dinis Silvestre, J., Gomes, M. G., Silva, L. and Ilharco, L. (2019). Physical, mechanical and microstructural characterization of a thermal insulating render incorporating silica aerogel: nanoSIR. Energy and Buildings, 211, 109793: doi.org/10.1016/j.enbuild.2020.109793

Santos, L. A., Flores-Colen, I. and Gomes, M. G. (2013). In-situ Techniques for Mechanical Performance and Degradation Analysis of Rendering Walls. Restoration of Buildings and Monuments, 19(4). doi: 10.1515/rbm-2013-6606

Sousa, R., Sousa, H., Silva, L., Flores-Colen, I. and Pedroso, M. (2019). Development of a wall system made with thermally optimized masonry and super insulation mortar render. Masonry International, 32(1), 3-14. https://www.scopus.com

Stahl, T., Ghazi Wakili, K., Hartmeier, S., Franov, E., Niederberger, W. and Zimmermann, M. (2017). Temperature and moisture evolution beneath an aerogel based rendering applied to a historic building. Journal of Building Engineering, 12, 140-146. doi: 10.1016/j.jobe.2017.05.016/ 